\title{
Mídias tradicional versus digital na concepção arquitetônica e seus reflexos na cognição
}

\author{
Traditional versus digital media in \\ architectural conception and its reflexes in \\ cognition
}

\begin{abstract}
Gisele Lopes de Carvalho
Doutora em Desenvolvimento Urbano

Professora Associado do Departamento de Expressão Gráfica, Universidade Federal de Pernambuco, Recife, Brasil giseledecarvalho@gmail.com
\end{abstract}

\section{Ney de Brito Dantas}

PhD em Arquitetura, Professor Associado do Departamento de

Arquitetura, Universidade Federal de Pernambuco, Recife, Brasil nd@hotlink.com,br

\section{RESUMO:}

Esta pesquisa objetiva relacionar os processos cognitivos dos arquitetos durante a concepção arquitetônica usando as mídias tradicionais e digitais. Dados empíricos foram coletados a partir da: (1) filmagem de dois grupos de sujeitos usando ambas as mídias a fim de executar duas tarefas isomórficas (projetos); (2) questionários e (3) análise dos protocolos verbais retrospectivos dessas tarefas. Esses grupos foram observados no Brasil e na Inglaterra. A análise de um esquema de códigos do comportamento projetual dos sujeitos (segmentações e categorias de ações cognitivas) possibilitou um estudo relacional da atividade projetual em termos das ações cognitivas primitivas adotadas pelos sujeitos nas duas mídias. Os resultados indicaram que a mídia tradicional ainda apresenta vantagens sobre a mídia digital devido tanto às limitações do estado da arte de hardware e software quanto à falta de compreensão e domínio da ferramenta computacional por parte do usuário. Algumas vantagens relacionadas ao uso da mídia tradicional foram: (1) fornecer ao arquiteto um suporte melhor à percepção dos aspectos visuais e espaciais e das relações organizacionais do projeto; (2) produzir mais soluções alternativas (transformações laterais) evitando cristalizações prematuras de soluções projetuais e (3) uma melhor compreensão do problema projetual.

Palavras-chave: cognição; computação gráfica; projetação; esboço; lápis.

\section{ABSTRACT:}

This research aims to relate the cognitive processes of architects during architectural conception using traditional and digital media. Empirical data were collected from: (1) two groups of subjects using both media in order to perform two videotaped isomorphic tasks (designs); (2) questionnaires and (3) analysis of verbal retrospective protocols of these tasks. These groups were observed at Brazil and at England. The analysis of a coding scheme of the design behaviour of each individual (segmentations and categorisations of the cognitive actions) allowed a relational study of the design activities in terms of the primitive cognitive actions adopted by them in each design media. The results indicated that traditional media still have advantages over digital media due to both the limitations of the state of the art of hardware and software and the lack of understanding and mastery of the computational tool by the user. Some advantages related to the use of traditional media were: (1) to provide the architect with a better support for the perception of the visual and spatial aspects and organizational relationships of the project; (2) to produce more alternative solutions (lateral transformations) avoiding premature crystallization of design solutions and (3) a better understanding of the design problem.

Keywords: cognition; computer graphics; design; sketch; pencil. 


\section{INTRODUÇÃO}

Toda representação gráfica é limitada e incompleta, apresentando deficiências em incorporar todos os elementos e atributos possíveis do espaço arquitetônico proposto. Apesar destas limitações, a representação gráfica é fundamental ao processo projetual arquitetônico.

0 esboço tem sido o principal meio de interação entre o arquiteto e o problema/proposta projetual, nos primeiros momentos da projetação, ajudando na conceituação e definição do problema. A rapidez no registro das ideias dá suporte às operações intelectuais do pensamento criativo, auxiliando a memória de curto prazo e o trabalho de análise e simulação que, paulatinamente, irão definindo a proposta.

A capacidade de representar graficamente os modelos que surgem na mente agrega pensamento visual e pensamento especificamente gráfico, ambos aperfeiçoados através da experiência e do treinamento. A representação gráfica pode ser usada para provocar pensamentos específicos e propositadamente alterar padrões de pensamento promovendo a imaginação e a inovação. Esta também dá suporte à análise e à definição do problema, geração de alternativas, avaliação, desenvolvimento e implementação do projeto.

LASEAU (1989) utiliza o termo 'pensamento gráfico' para descrever o pensamento auxiliado por esboços na fase de concepção de um projeto, na qual pensamento e esboços trabalham em conjunto impulsionando $o$ desenvolvimento da ideia. 0 processo do pensamento gráfico pode ser visto como uma conversação com nós mesmos, na qual nos comunicamos com os esboços. Laseau considera, também, que o pensamento gráfico requer quatro tipos de habilidades como suporte: observação, percepção, seletividade e imaginação. Nesta mesma obra, Laseau acrescenta que a comunicação através do desenho abrange a imagem desenhada, os olhos, o cérebro e as mãos, de modo que o potencial do pensamento gráfico reside no ciclo contínuo de troca de informações entre estes quatro elementos. Teoricamente, quanto mais a informação é passada através deste ciclo, maiores são as oportunidades de mudança.

Portanto, entender como estrutura-se a mediação exercida pelas tecnologias empregadas durante a concepção projetual é um caminho para a compreensão das influências que a adoção de mídias distintas pode ter no desenvolvimento deste processo. Nossa revisão bibliográfica aliada aos dados de pesquisas anteriores e a nossa experiência em sala de aula indicam que, na fase de concepção arquitetônica, existem diferenças significativas entre as ações cognitivas dos arquitetos quando estes utilizam a mídia digital ao invés da mídia tradicional.

Este trabalho objetiva investigar as implicações geradas pelo uso da computação gráfica na concepção arquitetônica, especificamente o modo como a computação gráfica vem modificando o pensamento projetual e a 
interação entre o arquiteto e a proposta/ problema projetual, durante a fase de concepção segundo uma abordagem cognitiva.

\section{METODOLOGIA}

Neste trabalho conduzimos um experimento de laboratório, sob condições controladas, para relacionarmos os processos cognitivos, de Arquitetos e estudantes de Arquitetura, durante a concepção arquitetônica utilizando-se de mídias distintas (instrumentos de desenho $\mathrm{X}$ recursos computacionais).

\subsection{O método: a análise de protocolos}

A Análise de Protocolos consiste na análise da verbalização dos pensamentos dos sujeitos (protocolos verbais) enquanto estão solucionando problemas. No presente estudo trabalhamos com relatórios retrospectivos, aplicamos um procedimento de análise com um esquema de códigos baseado no conteúdo (ou seja, uma abordagem informal) e um método de segmentação baseado no processo. O pré-processamento dos dados dos protocolos envolveu três etapas: a transcrição, a segmentação e a codificação.

\subsubsection{Categorias de Segmentação}

Após a análise dos protocolos visuais e verbais, criamos cinco categorias baseadas nas mudanças de metas e intenções mais comuns (vide a Tabela 1 a seguir). Dividimos os protocolos brutos em 'segmentos' segundo as linhas de intenções e ações apresentadas em comum pelos projetistas no desenvolvimento das tarefas. Uma mudança na intenção do sujeito, do conteúdo de seus pensamentos ou de suas ações sinaliza o começo de um segmento novo. Com isto, não queremos afirmar que estas categorias cubram todas as possíveis metas e ações do projetista no processo de resolução de problemas da projetação; mas, que é possível decompor todas as sessões projetuais nesta experiência nestas categorias.

\subsubsection{Categorias de Ações Cognitivas}

Durante o processo de concepção, diferentes sistemas do cérebro são ativados (visual, espacial, verbal e semântico). Cada segmento de protocolo compreende vários tipos de ações cognitivas. Para efeito de sistematização e análise dividimos as ações cognitivas dos sujeitos em: físicas, perceptivas, funcionais e conceituais, observando que as mesmas são dependentes e concomitantes entre si (DAMÁSIO, 2003). Estas categorias de ação são as mesmas usadas por (SUWA et.al., 1998), no entanto, as subcategorias foram adaptadas ao nosso caso específico, a fim de subsidiar a comparação entre as mídias (vide a Tabela 2 a seguir). 
Tabela 1: Categorias de Segmentação

\begin{tabular}{|c|c|}
\hline \multirow{6}{*}{$\begin{array}{l}\text { A. Define/ } \\
\text { cria um } \\
\text { espaço, um } \\
\text { volume, uma } \\
\text { estrutura ou } \\
\text { uma área }\end{array}$} & $\begin{array}{l}\text { 1. Menciona apenas o espaço (gesto, círculo, retângulo, linha) ou } \\
\text { desenha um espaço, volume, estrutura, coberta ou uma área. }\end{array}$ \\
\hline & $\begin{array}{l}\text { 2. Coloca coisas/objetos nos espaços desenhando ou mencionando } \\
\text { elementos espaciais (portas, janelas, paredes, pilares, piso etc.); móveis } \\
\text { (mesa, sofá, balcões, bancadas, acessórios etc.) ou equipamentos } \\
\text { (lavatório, chuveiro, bacia etc.). }\end{array}$ \\
\hline & 3. A combinação de 1 e 2 . \\
\hline & $\begin{array}{l}\text { 4. Preocupa-se ou resolve o dimensionamento de espaços ou } \\
\text { elementos }\end{array}$ \\
\hline & 5. A combinação de 1 e 4 . \\
\hline & 6. Comenta sobre um elemento ou conceito. \\
\hline \multirow{3}{*}{$\begin{array}{l}\text { B. Revisita } \\
\text { um espaço } \\
\text { para } \\
\text { detalhá-lo }\end{array}$} & $\begin{array}{l}\text { Adiciona elementos espaciais (janelas, portas, pilares, septos etc.) e/ou } \\
\text { mobília/acessórios, equipamentos, piso. }\end{array}$ \\
\hline & Define ou comenta sobre materiais, acabamentos ou revestimentos. \\
\hline & A combinação de 1 e 2 . \\
\hline \multirow{3}{*}{$\begin{array}{l}\text { C. Redefine } \\
\text { uma ideia ou } \\
\text { um espaço }\end{array}$} & $\begin{array}{l}\text { Transforma uma ideia ou um espaço (escala/translação/rotação/ } \\
\text { mudança na Geometria/combinação/proporção/ortogonalidade). }\end{array}$ \\
\hline & $\begin{array}{l}\text { Muda a organização da mobília ou equipamentos de acordo com } \\
\text { princípios geométricos (adjacência/simetria/reflexão/ortogonalidade) } \\
\text { ou de requerimentos funcionais ou plástico-volumétricos. }\end{array}$ \\
\hline & A combinação de 1 e 2. \\
\hline \multirow{3}{*}{$\begin{array}{l}\text { D. Definição } \\
\text { das relações } \\
\text { espaciais }\end{array}$} & Associa relações globais (espaço privado X espaço público entorno). \\
\hline & $\begin{array}{l}\text { Associa relações locais entre os espaços internos (divide os espaços; } \\
\text { define acessos, circulações, coberta; coloca uma porta, abertura, } \\
\text { parede; define simetria ou assimetria, proximidade ou afastamento } \\
\text { entre os espaços). }\end{array}$ \\
\hline & A combinação de 1 e 2. \\
\hline \multirow{3}{*}{$\begin{array}{l}\text { E. } \\
\text { Redefinição } \\
\text { das relações } \\
\text { espaciais }\end{array}$} & Redefine as relações globais. \\
\hline & $\begin{array}{l}\text { Redefine as relações locais através da relocação de um espaço ou da } \\
\text { relocação de portas ou da reorganização de coisas/objetos dentro ou } \\
\text { entre os espaços. }\end{array}$ \\
\hline & A combinação de 1 e 2. \\
\hline $\begin{array}{l}\text { F.Reprodução } \\
\text { do projeto }\end{array}$ & Copia o projeto desenhando ao lado ou em um novo papel. \\
\hline $\begin{array}{l}\text { G. } \\
\text { Perspectiva } \\
\text { do objeto } \\
\text { arquitetônico }\end{array}$ & $\begin{array}{l}\text { Representa o espaço interno ou externo em perspectiva ou olha para a } \\
\text { perspectiva representada. }\end{array}$ \\
\hline
\end{tabular}

Fonte: CARVALHO (2004).

Tabela 2: Categorias de Ações Cognitivas 


\begin{tabular}{|c|c|c|c|}
\hline Ação & Subcategoria & $\begin{array}{l}\text { Identidade } \\
\text { da Ação }\end{array}$ & Descrição \\
\hline \multirow[t]{6}{*}{ Física } & \multirow[t]{2}{*}{ Desenhar } & Fdn & $\begin{array}{l}\text { Faz novas representações (desenha linhas, } \\
\text { retângulos, paredes, espaços, objetos, mobília, } \\
\text { acessórios etc.). }\end{array}$ \\
\hline & & Fds & $\begin{array}{l}\text { Desenha um símbolo que represente uma } \\
\text { relação (apenas para o esboço a lápis). }\end{array}$ \\
\hline & \multirow[t]{3}{*}{ Modificar } & Fmr & $\begin{array}{l}\text { Revisa forma, tamanho ou textura de um } \\
\text { desenho. Estica linhas ou áreas, edita formas, } \\
\text { cores ou texturas. }\end{array}$ \\
\hline & & Fmd & $\begin{array}{l}\text { Apaga um desenho/ 'deleta' uma parede ou um } \\
\text { objeto. }\end{array}$ \\
\hline & & Fmm & $\begin{array}{l}\text { Move um desenho/objeto. Rotaciona um objeto } \\
\text { (apenas no ambiente CAD). }\end{array}$ \\
\hline & Copiar & Fco & $\begin{array}{l}\text { Copia um desenho ao lado ou em um novo } \\
\text { papel. }\end{array}$ \\
\hline \multirow[t]{6}{*}{ Perceptiva } & \multirow[t]{2}{*}{$\begin{array}{l}\text { Observar } \\
\text { características }\end{array}$} & Pcn & $\begin{array}{l}\text { Observa as características de um novo desenho } \\
\text { (forma, ângulo, tamanho, textura). }\end{array}$ \\
\hline & & Pc3d & $\begin{array}{l}\text { Observa as características de uma vista em 3D } \\
\text { (imaginária ou representada). }\end{array}$ \\
\hline & \multirow[t]{3}{*}{ Relacionar } & Prc & $\begin{array}{l}\text { Cria, atende, observa ou descobre uma relação } \\
\text { (espacial, geométrica ou organizacional) entre } \\
\text { dois ou mais objetos ou dois ou mais espaços. }\end{array}$ \\
\hline & & Prlo & $\begin{array}{l}\text { Observa a locação de um objeto (ou escala } \\
\text { humana) em um espaço componente } \\
\text { (alinhamento, distribuição ou definição } \\
\text { geométrica). }\end{array}$ \\
\hline & & Prle & $\begin{array}{l}\text { Observa a locação de um espaço em relação ao } \\
\text { objeto arquitetônico ou em relação ao entorno }\end{array}$ \\
\hline & $\begin{array}{l}\text { Descobrir } \\
\text { espaços } \\
\text { implícitos }\end{array}$ & Pie & $\begin{array}{l}\text { Descobre um espaço implícito, que surgiu como } \\
\text { pano de fundo entre os elementos } \\
\text { representados, sem ser previamente pensado. }\end{array}$ \\
\hline \multirow[t]{2}{*}{ Funcional } & $\begin{array}{l}\text { Implementar } \\
\text { funções }\end{array}$ & Fip & $\begin{array}{l}\text { Associa uma nova representação, característica } \\
\text { ou relação com uma função específica que foi } \\
\text { previamente pensada ou recentemente } \\
\text { descoberta. }\end{array}$ \\
\hline & $\begin{array}{l}\text { Pensar em } \\
\text { funções }\end{array}$ & $\mathrm{Fp}$ & $\begin{array}{l}\text { Pensa em uma função independentemente de } \\
\text { sua representação. }\end{array}$ \\
\hline \multirow[t]{3}{*}{ Conceitual } & $\begin{array}{l}\text { Determinar } \\
\text { metas }\end{array}$ & $\mathrm{Cdm}$ & $\begin{array}{l}\text { Determina metas. Introduz novas funções, } \\
\text { resolve conflitos e metas problemáticos, a fim } \\
\text { de aplicar funções ou arrumações. }\end{array}$ \\
\hline & $\begin{array}{l}\text { Relembrar } \\
\text { conhecimento }\end{array}$ & Crc & Relembra conhecimento. \\
\hline & $\begin{array}{l}\text { Avaliar } \\
\text { preferências }\end{array}$ & Cap & $\begin{array}{l}\text { Faz críticas ou avaliações preferenciais e } \\
\text { estéticas (gosta - não gosta; bom - mal; bonito - } \\
\text { feio). }\end{array}$ \\
\hline
\end{tabular}

Fonte: CARVALHO (2004).

\subsubsection{As Etapas do Experimento}


Etapa 1: Os 18 voluntários entre estudantes e Arquitetos (9 brasileiros da UFPE e 9 estrangeiros da Universidade de Sheffield) foram divididos em 2 grupos de nove.

Etapa 2: Foi feita uma apresentação sintética no PowerPoint dos objetivos e metodologia.

Etapa 3: Cada grupo concebeu dois projetos, considerados como tarefas isomórficas por apresentarem um grau de dificuldade semelhante (descritos a seguir nas Figuras 1 e 2).

Etapa 4: 0 Grupo I desenvolveu o primeiro projeto com lápis e papel e o segundo projeto no computador (em software de sua preferência); enquanto o Grupo II desenvolveu o primeiro projeto no computador e o segundo com lápis e papel. As tarefas foram filmadas para subsidiar a Análise dos Protocolos. As Figuras 3 e 4 exemplificam resultados das tarefas desenvolvidas no Lápis e no CAD.

Etapa 5: Assim que concluíam cada seção projetual, era pedido aos sujeitos, que recordassem e descrevessem o que pensaram enquanto desenvolviam cada tarefa, passo a passo. Para minimizar a omissão de detalhes devido ao declínio da memória de longo prazo, os vídeos do desenvolvimento da tarefa eram simultaneamente apresentados. As descrições foram gravadas em fita cassete. A Tabela 4 mostra um trecho do protocolo verbal do sujeito SB12 apresentando a segmentação e as respectivas categorias de ações cognitivas.

Etapa 6: Aplicação do questionário com os sujeitos.

Etapa 7: A influência da ordem das tarefas e a variação do tempo de desenvolvimento das mesmas foram analisados e comparados. Selecionamos, ainda, três juízes que analisaram os projetos graduando cada um deles a partir das seguintes categorias de análise: (1) Identidade; (2) Funcionalidade; (3) Dimensionamento; (4) Apresentação e representação gráfica; (5) Exequibilidade; (6) Estética. Estes juízes atribuíram conceitos a cada uma das categorias acima usando a escala de valores de Likert (Tabela 3) exemplificada abaixo:

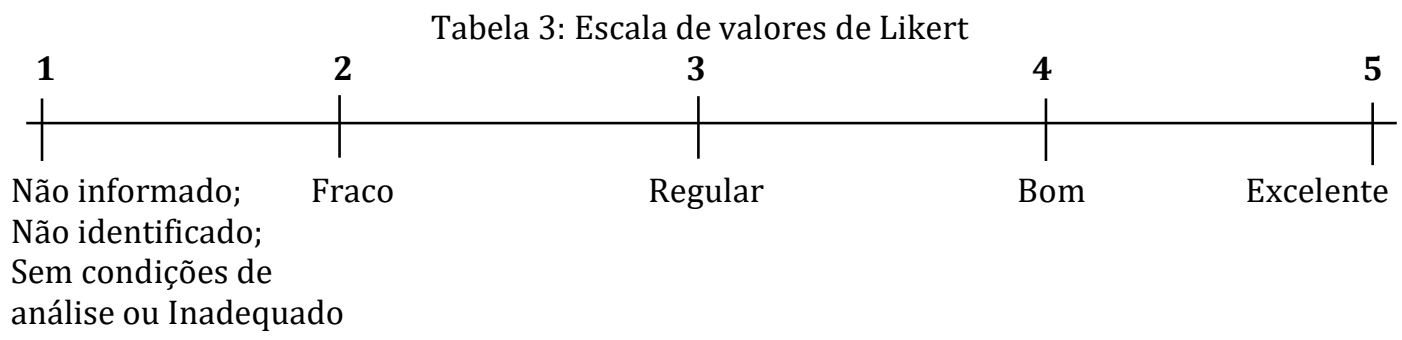

Fonte: PEREIRA (2001).

Figura 1: Tarefa 1: Bangalô de Praia 
Praia

\section{Hotel de Praia Existente}

Local: expansão hotel de praia existente;

Público alvo: casais em lua-de-mel;

Programa mínimo: 01 quarto; 01 BWC; 01 sala de estar; 01 copa (estilo americano); Área máxima $=40 \mathrm{~m}^{2}$.

Fonte: CARVALHO (2004).

Figura 2: Tarefa 2: Centro de Informação Turística

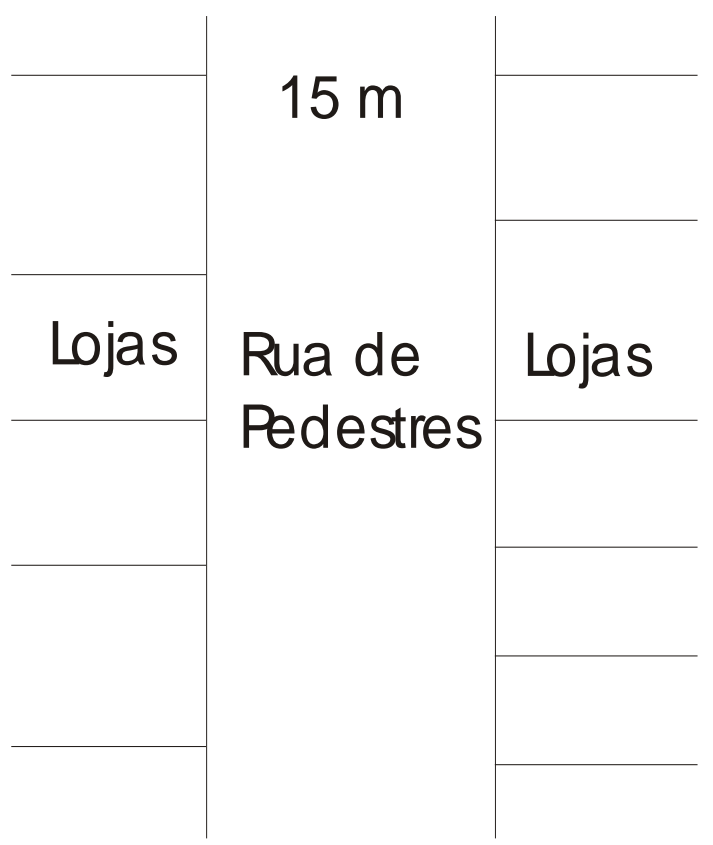

Local: Centro de pequena cidade histórica;

Público alvo: visitantes de todas as idades e nacionalidades;

Programa mínimo: 01 área principal de exposição; 01 administração; 01 copa; 01 WC;

Área máxima $=400 \mathrm{~m}^{2}$.

Fonte: CARVALHO (2004).

Figura 3 - Tarefa do sujeito SB12 desenvolvida com lápis 

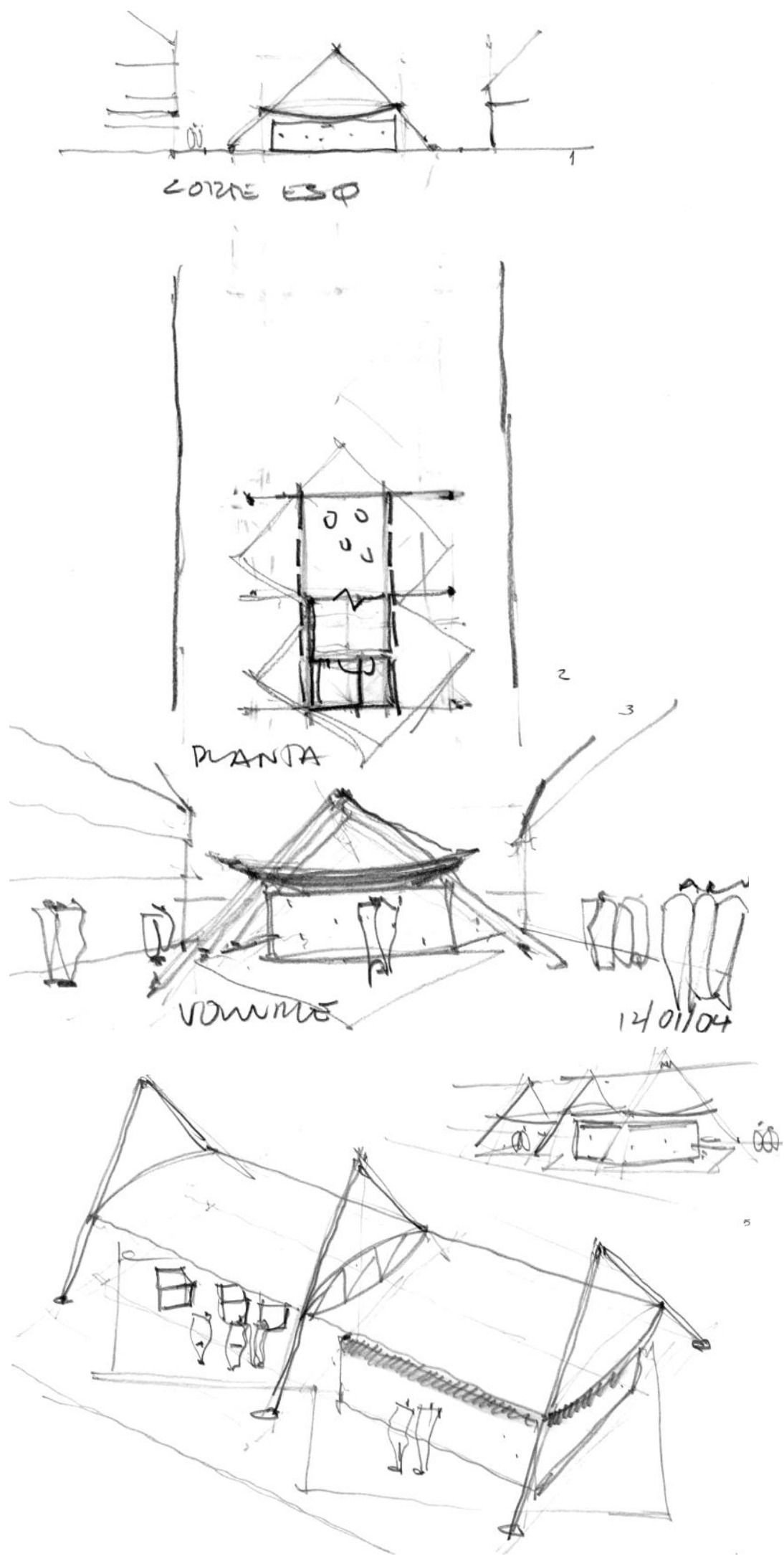

Fonte: CARVALHO (2004).

Figura 4 - Tarefa do sujeito SB12 desenvolvida no computador 

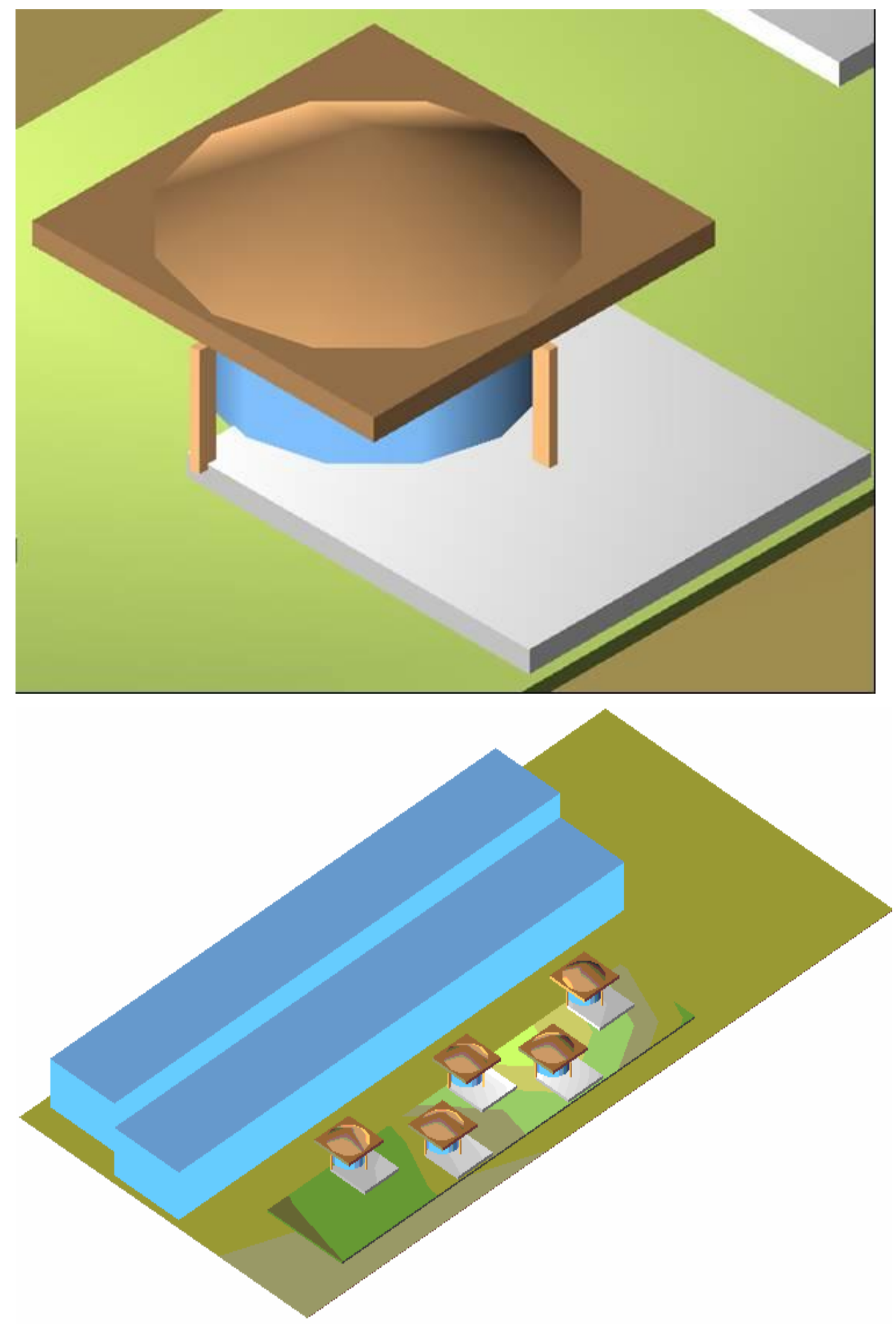

Fonte: CARVALHO (2004). 
Tabela 4 - Trecho do protocolo verbal do sujeito SB12 na tarefa com lápis

(Segmento 1: Tipo D1) Eu comecei a ver uma coisa que não interfira muito, que seja leve, aí você tem o conceito né? Uma cobertazinha bem simples que não tire a visão do entorno, aí de qualquer forma eu quis fazer um contraste do antigo com o novo, uma tecnologia mais moderna,

\begin{tabular}{l|l|l|l|l|l|l|l}
\hline \multicolumn{5}{c}{ SEGMENTO 1 - Tipo D1: Associa relações globais (espaço privado x entorno) } \\
\hline Físicas & Perceptivas & Funcionais & \multicolumn{2}{l}{ Conceituais } \\
\hline ID & Conteúdo & ID & Conteúdo & ID & Conteúdo & ID & Conteúdo \\
\hline & & & & Fp1 & $\begin{array}{l}\text { Função da } \\
\text { coberta: não } \\
\text { tirar a visão do } \\
\text { entorno }\end{array}$ & Cap1 & $\begin{array}{l}\text { 0 procedimento } \\
\text { foi o mesmo }\end{array}$ \\
\hline & & & Fp2 & $\begin{array}{l}\text { Pensou no } \\
\text { entorno }\end{array}$ & Cdm1 & $\begin{array}{l}\text { Uma coisa que } \\
\text { não interfira } \\
\text { muito }\end{array}$ \\
\hline & & & & & & Cdm2 & Que seja leve \\
\hline & & & & & & $\begin{array}{l}\text { Udma coberta } \\
\text { simples, não tirar } \\
\text { a visão do } \\
\text { entorno }\end{array}$ \\
\hline & & & & & & $\begin{array}{l}\text { Fazer um } \\
\text { contraste do } \\
\text { antigo com o } \\
\text { novo (usando } \\
\text { uma tecnologia } \\
\text { mais moderna) }\end{array}$ \\
\hline
\end{tabular}

(Segmento 2: Tipo A5) Como você falou no espaço urbano e a rua a primeira coisa foi o corte, noção de altura né, a largura.

\begin{tabular}{l|l|l|l|l|l|l|l}
\hline \multicolumn{7}{c}{ SEGMENTO 2 - Tipo A5: Menciona ou desenha um espaço e o dimensiona } \\
\hline Físicas & \multicolumn{2}{l}{ Perceptivas } & Funcionais & \multicolumn{2}{l}{ Conceituais } \\
\hline ID & Conteúdo & ID & Conteúdo & ID & Conteúdo & ID & Conteúdo \\
\hline $\begin{array}{l}\text { Fdn } \\
1\end{array}$ & $\begin{array}{l}\text { Desenhou corte esq. da } \\
\text { rua }\end{array}$ & $\begin{array}{l}\text { Prc } \\
1\end{array}$ & $\begin{array}{l}\text { Observando a relação } \\
\text { entre o edf. e o } \\
\text { entorno }\end{array}$ & Fip1 & $\begin{array}{l}\text { Pensou nas } \\
\text { alturas e } \\
\text { larguras }\end{array}$ & & \\
\hline $\begin{array}{l}\text { Fdn } \\
2\end{array}$ & Desenhou o edf. na rua & $\begin{array}{l}\text { Prl } \\
\text { e1 }\end{array}$ & Locou o edf. na rua & & & & \\
\hline
\end{tabular}

Fonte: CARVALHO (2004).

\section{RESULTADOS, ANÁLISE ESTATÍSTICA E DESCOBERTAS}

\subsection{Introdução}

Objetivando a síntese do trabalho não apresentaremos todas as análises estatísticas feitas, mas apenas os resultados mais relevantes. A fim de subsidiar nossa análise estatística utilizamos o software SPSS (PEREIRA, 1999).

Como nossa amostra foi construída por voluntários, esta não representa um retrato do universo, visto que estes são mais interessados que a média. Por não observarmos uma diferença cultural significante evitamos apresentar comparações entre os sujeitos brasileiros e estrangeiros. 
Quase todos os projetistas, independentemente da mídia, adotaram uma abordagem de projeto de cima para baixo, partindo de um nível mais alto (abstrato) de decisões para os detalhes.

Apesar de se utilizarem de táticas semelhantes, todos os projetistas começaram o processo projetual de modo distinto, enfatizaram pontos distintos e apresentaram resultados sempre diferentes; então, as ferramentas precisam apresentar o máximo de flexibilidade e o mínimo de esforço e customização.

\subsection{Análise das Tarefas}

Os projetistas, em sua maioria, perceberam os softwares de computação gráfica como sendo menos produtivos na fase de concepção. Isto pode ser atribuído tanto a problemas com software e hardware como à falta de domínio do software utilizado por parte dos sujeitos.

\subsubsection{Tempo das tarefas}

Os projetistas levaram em média mais tempo para desenvolver a tarefa na mídia digital $(33,17$ minutos) enquanto que na mídia tradicional eles desenvolveram a tarefa levando em média 18,44 minutos (vide Tabela 5). Ao testarmos este resultado a partir da Prova de Wilcoxon verificamos que este era estatisticamente muito significante $(Z=-3.055$; significância=0.002).

Tabela 5 - Duração média das seções em minutos

\begin{tabular}{l|l|l}
\hline Duração média das seções em minutos & Lápis & Computador \\
\hline Todos os sujeitos & 18,44 & 33,14 \\
\hline Sujeitos brasileiros & 25,55 & 38,33 \\
\hline Sujeitos estrangeiros & 11,33 & 28,00 \\
\hline
\end{tabular}

\subsubsection{Domínio das ferramentas}

Dos dezoito projetistas que participaram da pesquisa, apenas um não apresentou um domínio suficiente do uso do lápis comprometendo a representação de suas ideias enquanto que no computador, sete projetistas não apresentaram domínio suficiente da ferramenta (vide Tabela 6). Embora esta diferença não tenha se apresentado significativa ao aplicarmos a Prova de Wilcoxon $(\mathrm{Z}=-1.542$; significância=0.111), talvez, aumentando o número de sujeitos pudéssemos obter um resultado mais significativo.

No computador os projetistas limitaram-se a usar formas ortogonais ou geométricas regulares, baseando suas escolhas na facilidade de representação, bem como a falta de domínio do software limitou e comprometeu a solução arquitetônica. 
Tabela 6 - Percentagem de sujeitos que apresentaram um domínio insuficiente da ferramenta.

\begin{tabular}{l|l|l}
\hline Percentagem de sujeitos com domínio insuficiente da ferramenta & LÁPIS & CAD \\
\hline Todos os sujeitos & $5,55 \%$ & $38,89 \%$ \\
\hline
\end{tabular}

Fonte: CARVALHO (2004).

\subsubsection{Plantas apresentadas}

A maioria dos projetistas, quando utilizando lápis e papel, usaram representações múltiplas para construir a configuração espacial. Doze deles apresentaram plantas e perspectivas, às vezes combinadas com cortes e/ou fachadas, quatro deles apresentaram plantas e cortes e/ou fachadas e apenas dois representaram unicamente plantas baixas. Em contrapartida, quando se utilizando da mídia digital, a maioria dos projetistas (dez deles) representaram seus projetos usando apenas plantas baixas (vide Tabela 7). Ao testarmos os resultados a partir da Prova de Wilcoxon observamos que estas diferenças entre as mídias eram estatisticamente muito significantes $(\mathrm{Z}=-2.879$, significância=0.004).

Alguns projetistas na mídia a lápis usaram formas esquemáticas de representação (diagrama de bolhas ou formas geométricas). Observamos que os projetistas passavam bastante tempo parados, refletindo diante da tela do computador, enquanto que na mídia tradicional estes encontravam-se sempre rabiscando. Também, que muitas ações físicas não ficam registradas no computador, pois o hábito de apagar é muito mais frequente nesta mídia do que no lápis e papel.

Tabela 7 - Percentagem de sujeitos que representou apenas plantas baixas

\begin{tabular}{l|l|l}
\hline $\begin{array}{l}\text { Percentagem de sujeitos que representou apenas plantas } \\
\text { baixas }\end{array}$ & LÁPIS & CAD \\
\hline Todos os sujeitos & $11,11 \%$ & $55,56 \%$ \\
\hline Sujeitos brasileiros & $11,11 \%$ & $44,44 \%$ \\
\hline Sujeitos estrangeiros & $11,11 \%$ & $66,67 \%$ \\
\hline \multicolumn{2}{c}{}
\end{tabular}

\subsubsection{Número de soluções apresentadas}

No esboço à mão livre quando uma nova ideia surge, rapidamente se segue um número de variações da mesma, expandindo o espaço do problema. No computador quando uma ideia é gerada, sua representação externa parece fixar e reprimir novas explorações. A maioria dos esforços subsequentes, são devotados ao detalhamento e refinamento da mesma ideia. Exemplificando isso com números da pesquisa, observamos que, no computador, dos dezoito projetistas pesquisados, treze apresentaram a primeira ideia como única solução para o problema enquanto que no lápis e papel apenas sete projetistas apresentaram uma só solução. Os demais ou apresentaram várias opções para uma mesma ideia ou até mesmo soluções distintas (vide Tabela 8). Ao testarmos os resultados a partir da Prova de Wilcoxon constatamos que estas 
diferenças eram estatisticamente significantes $\quad(Z=-2.333$; significância=0.020).

Tabela 8 - Percentagem de sujeitos que apresentou apenas uma solução

\begin{tabular}{l|l|l}
\hline Percentagem de sujeitos que apresentou apenas uma solução & LÁPIS & CAD \\
\hline Todos os sujeitos & $38,89 \%$ & $72,22 \%$ \\
\hline Sujeitos brasileiros & $33,33 \%$ & $66,67 \%$ \\
\hline Sujeitos estrangeiros & $44,44 \%$ & $77,78 \%$ \\
\hline
\end{tabular}

Fonte: CARVALHO (2004).

Acreditamos que essa cristalização na primeira ideia se dá pelo fato do software impor uma rigidez na fase inicial de projetação, pois este ainda não dispõe de recursos mais interativos e flexíveis que correspondam à rapidez do ciclo representação mental - habilidade manual - representação gráfica que caracteriza esta fase. Os arquitetos são capazes de pensar sobre uma edificação de muitos modos distintos ao mesmo tempo (como invólucros, espaços, superfícies, etc.), isso é o que (LAWSON, 1998) denominou de linhas paralelas de pensamento. Mas, o computador conta com uma estrutura interna que não reflete os modos e características usados pelos arquitetos na concepção.

\subsubsection{Análise das Tarefas feita pelos Juízes}

Tabela 9 - Média das Notas dos 3 Juízes

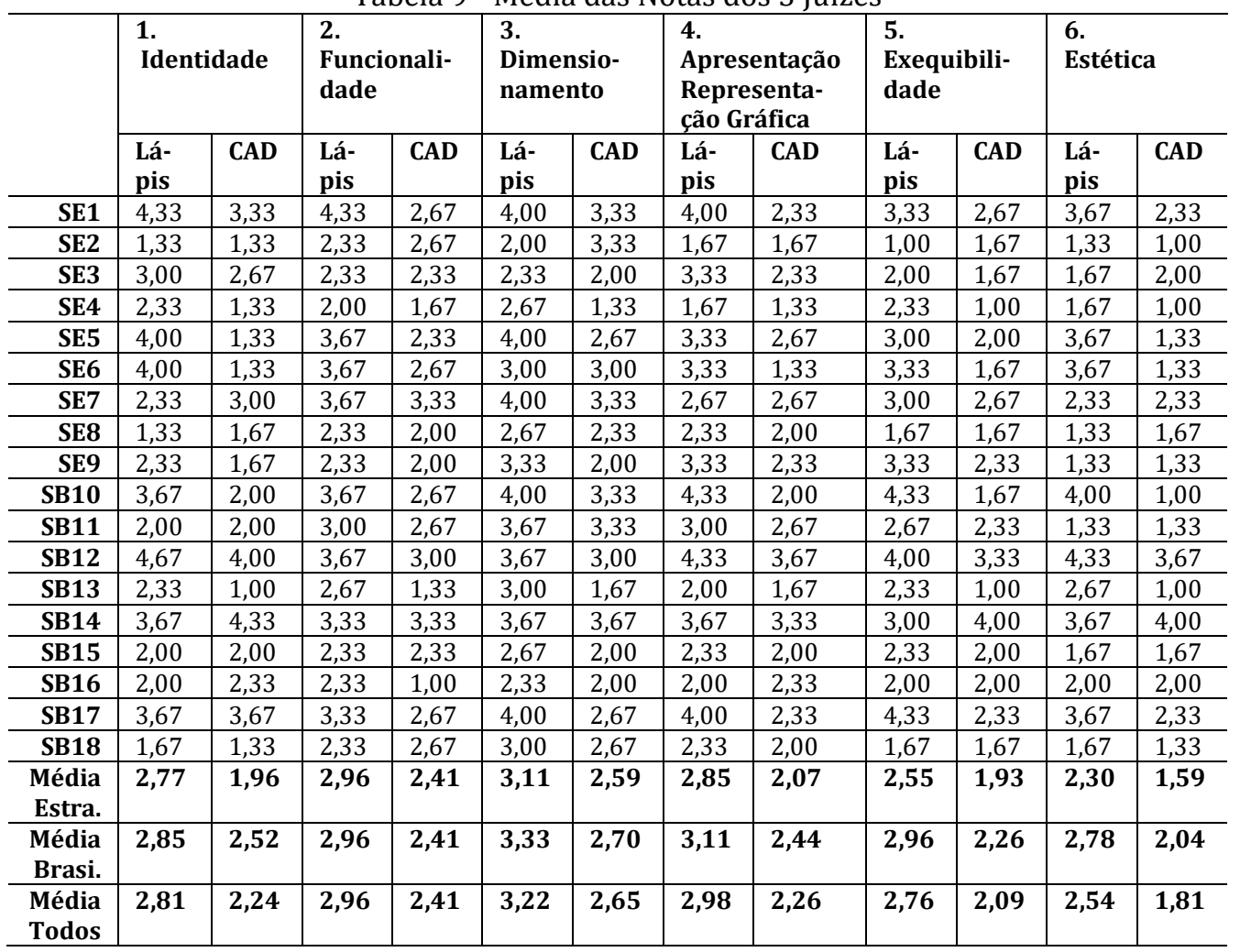

Fonte: CARVALHO (2004).

Ao compararmos as médias e os desvios-padrão das notas dos juízes observamos que, os sujeitos saíram-se melhor quando usando a mídia lápis e papel (vide Tabela 9) em todas as categorias analisadas. Ao testarmos os 
resultados a partir da Prova de Wilcoxon também pudemos constatar que esta diferença era estatisticamente significante para todas as categorias: identidade (significância= 0.03); funcionalidade (significância= 0.006); dimensionamento (significância= 0.004); apresentação e representação gráfica (significância= 0.001); exequibilidade (significância=0.011); estética (significância $=0.010$ ).

\subsection{Análise dos Dados e Resultados Relacionados às Categorias de Segmentação}

Independentemente da ordem em que as tarefas foram desenvolvidas, o número de segmentos por minuto de seção era maior nas sessões LÁPIS do que nas sessões CAD (vide figura 5 e Tabela 10) apresentando apenas um sujeito brasileiro como exceção.

Figura 5 - Número de segmentos por minuto de tarefa em (a) sessões CAD-LÁPIS e em (b) sessões LÁPIS-CAD
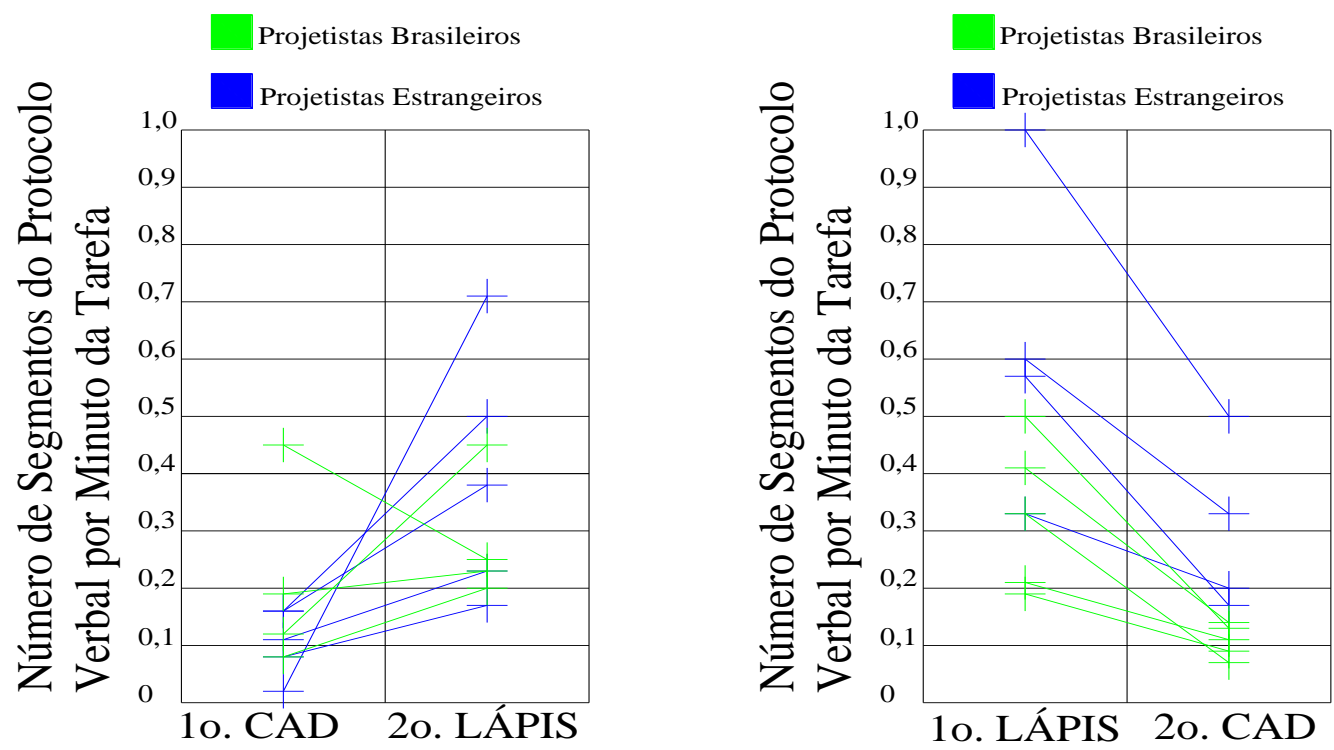

Fonte: CARVALHO (2004).

Tabela 10 - Número médio de segmentos por minuto de seção

\begin{tabular}{l|l|l}
\hline Número médio de segmentos por minuto de seção & LÁPIS & CAD \\
\hline Todos os sujeitos & 0,40 & 0,17 \\
\hline Sujeitos brasileiros & 0,31 & 0,15 \\
\hline Sujeitos estrangeiros & 0,50 & 0,20 \\
\hline
\end{tabular}

Fonte: CARVALHO (2004).

Ao testarmos os resultados a partir da Prova de Wilcoxon observamos que estes eram estatisticamente muito significantes $(\mathrm{Z}=-3.376$; significância $=0.001$ ).

Na mídia tradicional além do número de segmentos ser mais alto, estes foram mais densamente ordenados, significando que os projetistas mudaram 
suas tomadas de decisões e metas mais frequentemente quando usaram a mídia tradicional.

Os projetistas têm uma tendência geral, independentemente da mídia, de resolver o problema de planejamento do espaço começando pela divisão do layout das áreas (relações globais) e depois abordado as relações locais entre os componentes.

A frequência de trocas de estratégias depende das características de resolução de problemas do projetista. No entanto, a partir da análise das submetas na estratégia ramificada, identificamos um perfil do processo de concepção das tarefas dadas para todos os sujeitos (vide a figura 6 a seguir):

Figura 6 - Processo de Concepção das Tarefas dadas

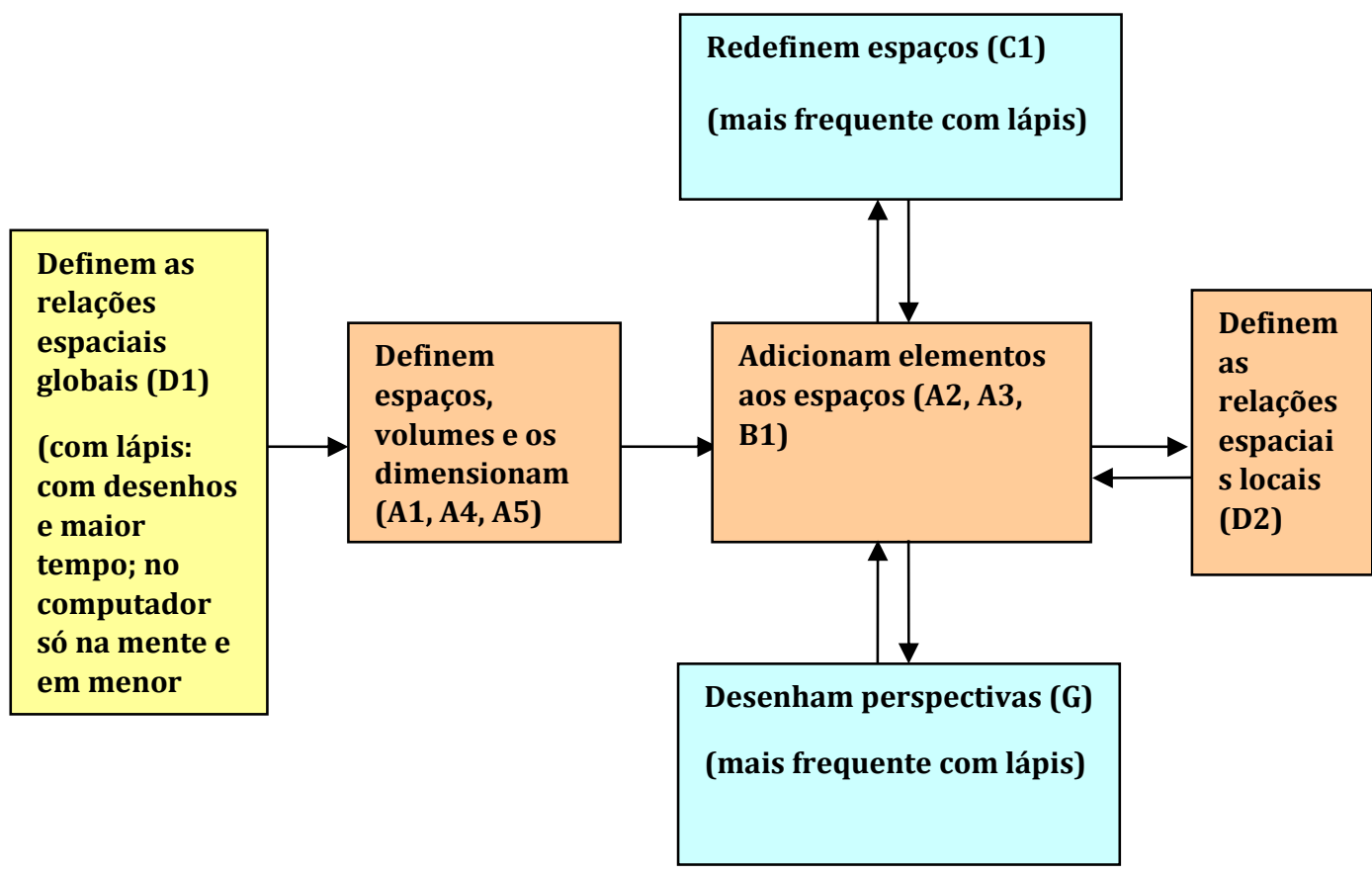

Fonte: CARVALHO (2004).

Quando os arquitetos esboçam no papel, eles associam suas representações com significados, estruturas, operações e especificações, dinamicamente, apenas quando se faz necessário e não no momento em que estas são feitas. Um projeto não aparece completo na mente de um arquiteto, este é gradualmente desenvolvido e refinado. Portanto, no lápis observamos uma maior redefinição de espaços bem como o uso maior de perspectivas (vide a figura 6 acima).

\subsection{Análise dos Dados e Resultados Relacionados às Ações Cognitivas (AC)}

Ao comparamos as médias e os desvios-padrão do número de ações cognitivas do protocolo verbal por minuto de tarefa quando usando mídias distintas constatamos que, em média, o número de ações cognitivas do 
protocolo verbal por minuto de tarefa é bem maior quando usando lápis e papel (vide Figura 7). Ao testarmos os resultados a partir da Prova de Wilcoxon também verificamos que esta diferença era estatisticamente muito significante $(Z=-3.724$; significância $=0.000)$.

Figura 7 - Número de AC por minuto de tarefa em (a) sessões CAD-LÁPIS (b) sessões LÁPISCAD

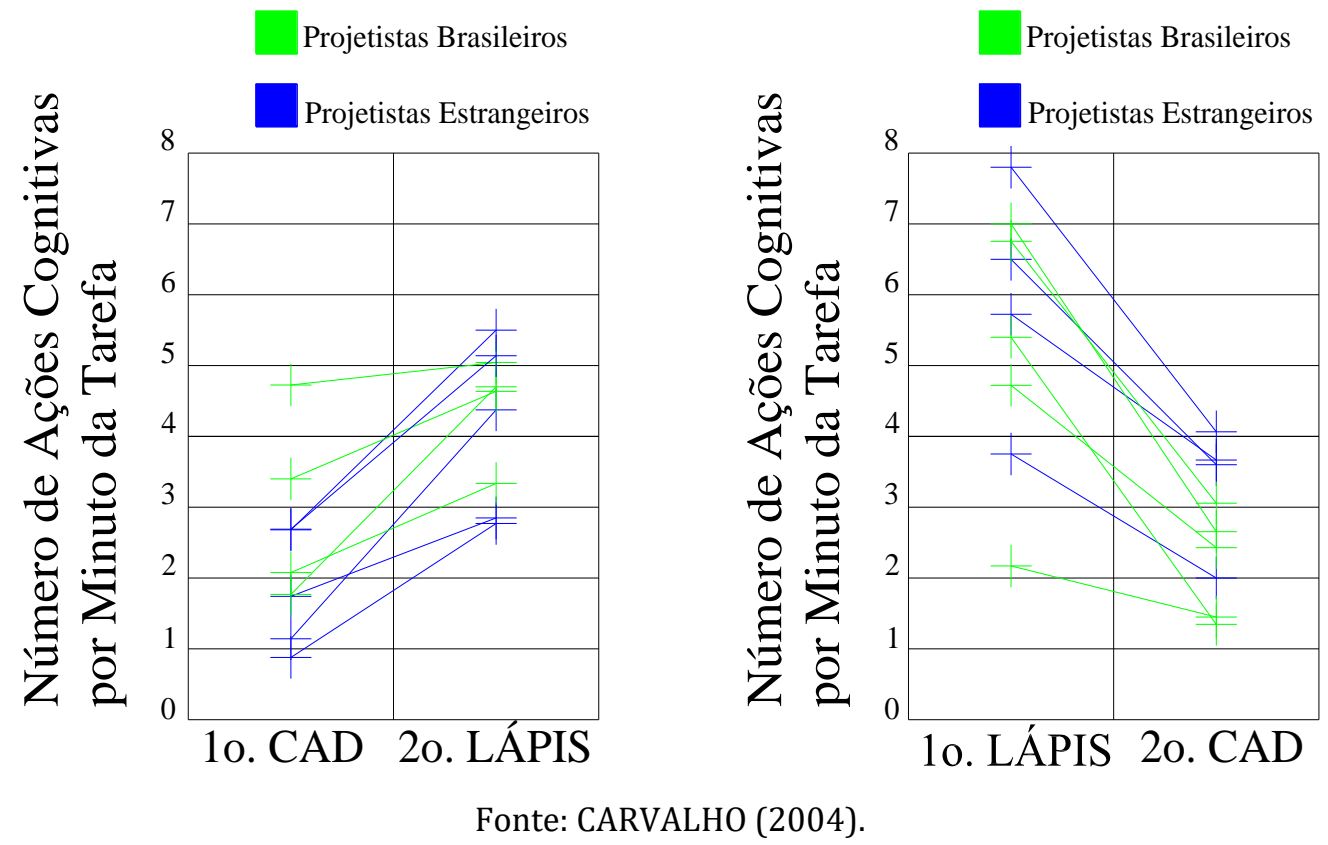

Também, ao testarmos individualmente as ações físicas, perceptivas, funcionais e conceituais pudemos constatar que em média a frequência de todas é bem maior na mídia lápis com diferenças estatisticamente muito significantes (CARVALHO, 2004).

Os dados testados estatisticamente são internos e não podem ser generalizados. No entanto, tendo em vista o grande número de ações em cada protocolo, podemos fazer afirmações razoavelmente bem fundamentadas baseadas nas evidências encontradas.

\section{5. $\quad$ Análise dos Dados e Resultados Relacionados ao Questionário}

As características significativamente associadas ao lápis e papel (abstração, raciocínio de projeto, liberdade, ordenação dos pensamentos, percepção e esboços sem medidas), também são as consideradas, como as mais importantes à fase de concepção.

As habilidades cognitivas consideradas, em média, como um pouco prejudicadas pelo uso do computador (criatividade/ imaginação, intuição/ inspiração) também foram consideradas, em média, muito importantes na fase de concepção do projeto. 
A grande maioria dos pesquisados (14 sujeitos - 77,78\%) só começa a trabalhar no computador quando a ideia já foi definida no lápis. Reafirmando o uso do computador mais como uma ferramenta de desenho que como uma ferramenta de concepção.

Treze sujeitos $(72,22 \%)$ afirmaram considerar o lápis e papel como meio mais rápido para conceber ideias de projeto. 0 resultado encontrado no desenvolvimento das tarefas isomórficas confirmou a expectativa da maioria.

Todas as afirmações acima foram testadas estatisticamente apresentando significância.

\section{DISCUSSÃO E CONSIDERAÇÕES FINAIS}

As mídias tradicionais, se comparadas às mídias digitais atualmente usadas, são mais fluidas e mais apropriadas para o desenvolvimento rápido inicial das ideias, o estímulo à imaginação, à investigação livre, à referência cruzada intencional e randômica de fontes diversas, à manipulação e visualização da escala, à expressão de estados emocionais etc.

As mídias digitais são bastante adequadas às fases de desenvolvimento do projeto já que estas exigem níveis mais altos de definição geométrica e a elaboração e coordenação de complexidade e detalhes, permitindo a fácil articulação e a geração de múltiplos pontos de vista (visualização); bem como o acesso e a manipulação da informação, o armazenamento de modelos e imagens, a geração de renderizações e simulações hiper-realistas.

Ao compararmos nossas variáveis, observamos que quando os sujeitos trabalharam usando lápis e papel apresentaram em média: (1) um melhor domínio da ferramenta; (2) um maior número de soluções de projeto; (3) um maior número de desenhos; (4) representações múltiplas; (5) melhor utilização do espaço; (6) um tempo menor para desenvolvimento da tarefa; (7) um maior número de segmentos no protocolo verbal; (8) um maior número de ações cognitivas e (9) melhores médias na avaliação dos juízes para todas as categorias analisadas (escala, proporção, dimensionamento, funcionamento, identidade, apresentação e representação gráfica, exequibilidade e estética). Ao testarmos estatisticamente estas diferenças entre as duas mídias observamos que com exceção da primeira (um melhor domínio da ferramenta), todas as diferenças eram estatisticamente significantes. Sendo assim, podemos concluir com um erro menor que $5 \%$ que:

Na fase específica de concepção do projeto, a mídia tradicional (lápis e papel) ainda apresenta vantagens sobre a mídia digital (computador) devido às limitações do estado da arte de hardware e software e das estratégias de abordagem atualmente adotadas pelos arquitetos em relação à mídia digital.

Também podemos concluir que:

1. A forma como a ferramenta computacional estrutura-se e constrói sua interface com o usuário impõe níveis de precisão, rigidez e compromisso que pressionam o arquiteto a tomar decisões antes que este esteja preparado a fazê-las; 
2. A falta de compreensão e domínio da ferramenta computacional por parte do usuário limita a utilização da computação gráfica tornando-a mais uma ferramenta de representação do que de concepção;

3. Existem diferenças significativas entre as ações cognitivas dos arquitetos, na fase de concepção de projeto, quando estes utilizam mídias distintas (lápis X software no computador);

4. 0 uso da mídia tradicional favorece uma melhor compreensão do problema projetual.

Mesmo com os avanços já apresentados, os atuais softwares de computação gráfica são bastante impositivos, não oferecendo suporte à imprecisão e à incerteza e, portanto, frequentemente, fixam ou cristalizam conceitos projetuais em desenvolvimento.

Durante a concepção de um projeto, uma grande variedade de alternativas é rapidamente considerada e comparada. 0 arquiteto trabalha de modo abstrato e sem compromisso, empregando diagramas e esboços para representar o projeto e explorar soluções alternativas, evitando pensar prematuramente sobre os detalhes. 0 arquiteto rapidamente explora uma variedade de soluções sem o esforço ou o compromisso dos desenhos mais elaborados.

0 arquiteto parte de um desenho diagramático para desenhos mais específicos, mais detalhados e mais comprometidos. 0 trabalho, a partir da abstração para os detalhes específicos, com o aumento gradual do comprometimento e da precisão, faz da projetação um processo de aumento da formalização. Portanto, podemos pensar sobre projetação como um processo de adicionar limites e de explorar o espaço projetual que estes limites determinam.

A representação no computador tem, na maioria das vezes, ignorado esta progressão dos diagramas abstratos para os desenhos detalhados preocupando-se mais em dar suporte às fases finais da projetação. 0 computador requer do arquiteto a identificação específica e precisa dos elementos e das relações entre eles, dificultando bastante o adiamento da tomada de decisões e, assim, não permite a abstração e a ambiguidade características da concepção. Portanto, a grande maioria dos arquitetos permanece utilizando lápis e papel na concepção e trazem o projeto para o computador apenas quando o trabalho alcança um estágio apropriado ao esforço, comprometimento e precisão que o computador exige. Um software de computação gráfica típico, seja ele CAD e se for BIM ainda pior, faz com que $\mathrm{o}$ arquiteto trabalhe demais e suas representações precisas pressionam o arquiteto a tomar decisões específicas antes que este esteja preparado a fazêlas.

As representações dos softwares de computação gráfica ainda não desempenham um bom trabalho no sentido de 'casar' com as representações mentais usadas pelos arquitetos.

Quando o arquiteto é obrigado a traduzir ideias de projeto em 
representações no software, isto interfere no projeto. Os softwares deveriam permitir que os arquitetos usassem processos mentais familiares e com um mínimo de intrusão. Infelizmente, a maioria deles ou força o usuário a traduzir ideias arquitetônicas nos termos dos sistemas ou a tentar pensar em termos de elementos do mesmo. Portanto, podemos constatar que o despreparo humano em lidar com a tecnologia, tanto por parte dos que a geram como por parte dos que a utilizam, determina a subutilização do enorme potencial que as ferramentas computacionais apresentam, gerando uma visão distorcida da tecnologia e de sua participação no processo projetual. No entanto, mesmo apresentando limitações, oferecem recursos, aplicáveis à projetação arquitetônica, capazes de estabelecer um modo totalmente novo de interação entre o arquiteto e o problema/proposta projetual.

Nos softwares de computação gráfica correntes, nenhum dos componentes do processo criativo, tais quais a percepção, a memória, o raciocínio, a imaginação, a abstração, a formação de conceitos e a resolução de problemas, parece ser muito bem suportado. A combinação, por exemplo, é demorada e a reestruturação quase não é suportada. Então, estes não parecem apropriados para apoiar o processo criativo da concepção de ideias. As mesas eletrônicas de esboço que, como papel e lápis, dão suporte à entrada de dados não especificados e deixam as tarefas de combinação e de reestruturação a cargo do projetista parecem ser, por enquanto, as ferramentas eletrônicas para a criação de ideias mais apropriadas. No entanto, atualmente, faltam a estas mesas, ferramentas de apoio para a reestruturação. A eficiência destas mesas, poderia ser consideravelmente melhorada, se ferramentas que permitissem olhar para a mesma coisa de outro modo, fossem fornecidas.

Embora a mídia digital possa parecer inconveniente à fase de concepção projetual, isto vai depender dos hábitos projetuais dos projetistas e da inflexibilidade/ flexibilidade do software utilizado. Visto que, o modo como nós lidamos atualmente com a noção das representações mentais via computador não faz justiça a todo o alcance da atividade simbólica humana.

Portanto, o que pudemos constatar até aqui é que as técnicas computacionais se encontram numa fase temporária de desenvolvimento e de adaptação. Ainda nos encontramos bastante restringidos tanto por nossa imaginação quanto por limitações da tecnologia corrente. Mas, a história tem nos sugerido que estes obstáculos, provavelmente, serão removidos em um futuro próximo. E, a partir do desenvolvimento de hardware e software e da adaptação do homem à mídia, o computador irá estabelecer uma nova relação com a atividade projetual.

Se conseguíssemos compreender melhor o pensamento projetual, poderíamos, conjuntamente com os programadores de software, tornar o mesmo mais adequado à concepção arquitetônica. Aproximaríamos, assim, o arquiteto do computador nesta fase, para que ele se sentisse tão ou mais estimulado para desenvolver suas ideias no computador que com o lápis e o papel. 
Outro ponto importante seria a compreensão, por parte dos arquitetos, dos novos processos cognitivos gerados pela utilização da computação gráfica. Assim, estes poderiam tirar proveito dos computadores como meios complementares de suas atividades mentais básicas.

Propomos deste modo, um processo interativo: o homem adaptando-se ao computador e o computador adaptando-se ao homem; do paradigma para a prática e desta de volta ao paradigma e, do computador para o lápis e papel e destes de volta para o computador. Deste modo, buscaremos compreender as similaridades, diferenças e limitações de ambas as mídias - lápis e computador - a fim de que possamos melhorar a utilização das ferramentas e oferecer recomendações aos desenvolvedores de hardware e software para que esses possam gerar sistemas mais capazes de dar suporte ao trabalho criativo da concepção projetual.

\section{REFERÊNCIAS BIBLIOGRÁFICAS}

CARVALHO, G. L. de Ambientes cognitivos para projetação: um estudo relacional entre as mídias tradicional e digital na concepção do projeto arquitetônico, 260 f. Tese (doutorado), Universidade Federal de Pernambuco. CAC. Desenvolvimento Urbano, 2004.

DAMÁSIO, A. Ao Encontro de Espinosa - As Emoções Sociais e a Neurologia do Sentir. Portugal: Publicações Europa-América, 2003.

FINKE, R. A.; WARD, T. B.; SMITH, S. M. Creative Cognition, Theory, Research and Applications. Cambridge, MA: MIT Press, 1992.

LASEAU, P. Graphic Thinking for Architects and Designers. $2^{\text {nd }}$ ed. New Yor: Van Nostrand Reinhold, 1989.

LAWSON, B. Towards a computer-aided architectural design process: a journey of several mirages. Computers in Industry, v. 35, n. 1, p. 45-57, February 1998.

PEREIRA, A. Guia Prático de Utilização do SPSS - Análise de Dados para Ciências Sociais e Psicologia. Lisboa: Edições Silabo, 1999.

PEREIRA, J. C. R. Análise de Dados Qualitativos: Estratégias Metodológicas para as Ciências da Saúde, Humanas e Sociais. 3a ed., São Paulo: Edusp, 2001.

SUWA, M.; PURCELL, T.; GERO, J. Macroscopic analysis of design processes based on a scheme for coding designers' cognitive actions. Design Studies, v. 19, n. 4, p. 455-483, Oct. 1998. 